\title{
A global methodology for catalyst screening and optimization process. Application to Mild Hydrocracking
}

Luc Davy1, J. Castro2, R. Wessels2, M. Rey-Bayle1, I.Merdrignac1, B. Celse1

1IFP Energies Nouvelles, Rond-point de l'échangeur de Solaize, 69360 Solaize, France

2Avantium Chemicals B.V., Zekeringstraat 29, 1014 BV Amsterdam, The Netherlands

Corresponding author: Benoit.celse@ifpen.fr 
Figure S1: Mass Balances during the catalysts evaluation (HTT)

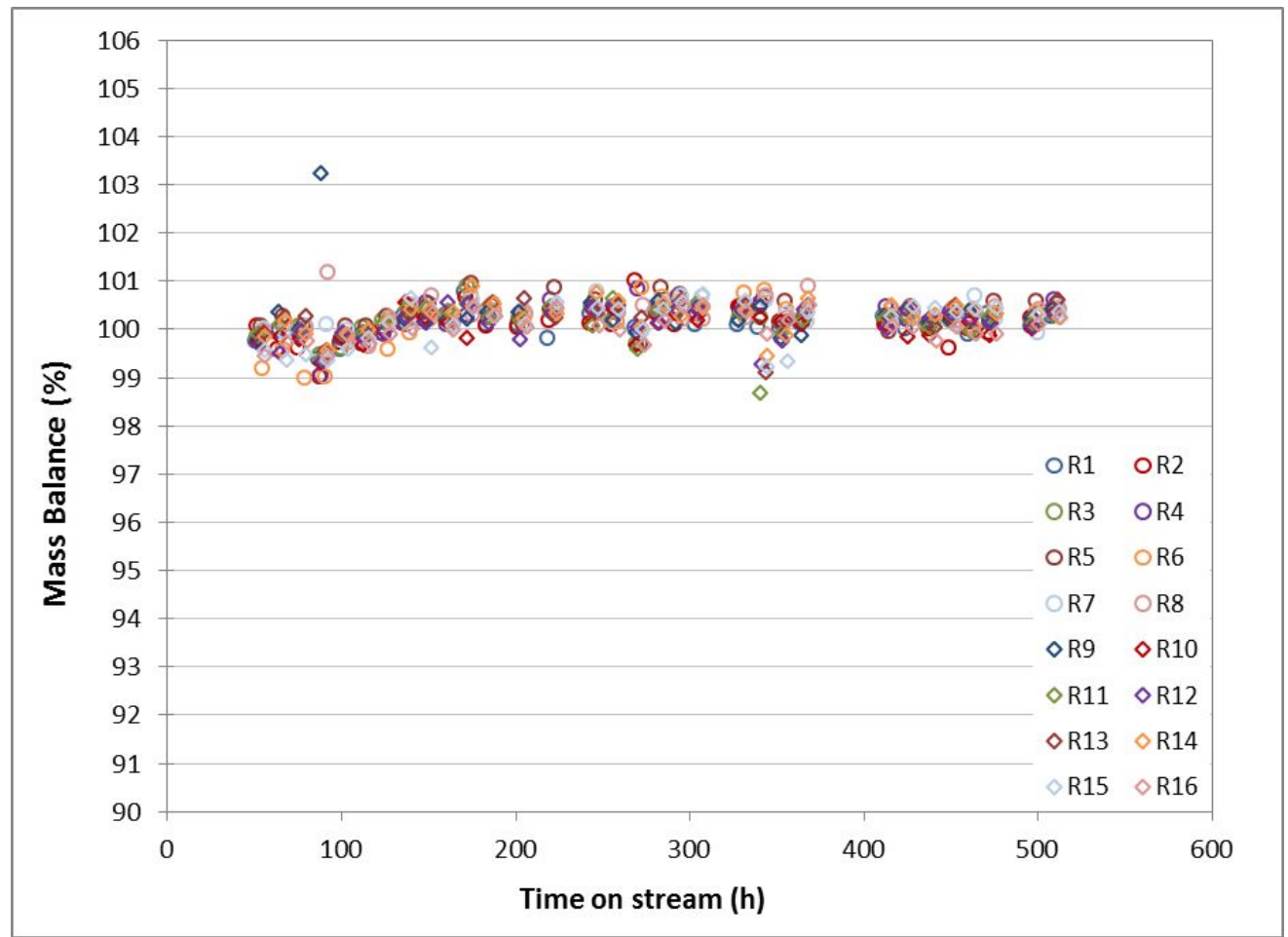

Figure S2: Net Conversion $370^{\circ} \mathrm{C}+$ with Temperature (Feed A, LHSV $=4 \mathrm{~h}^{-1}$ ) 


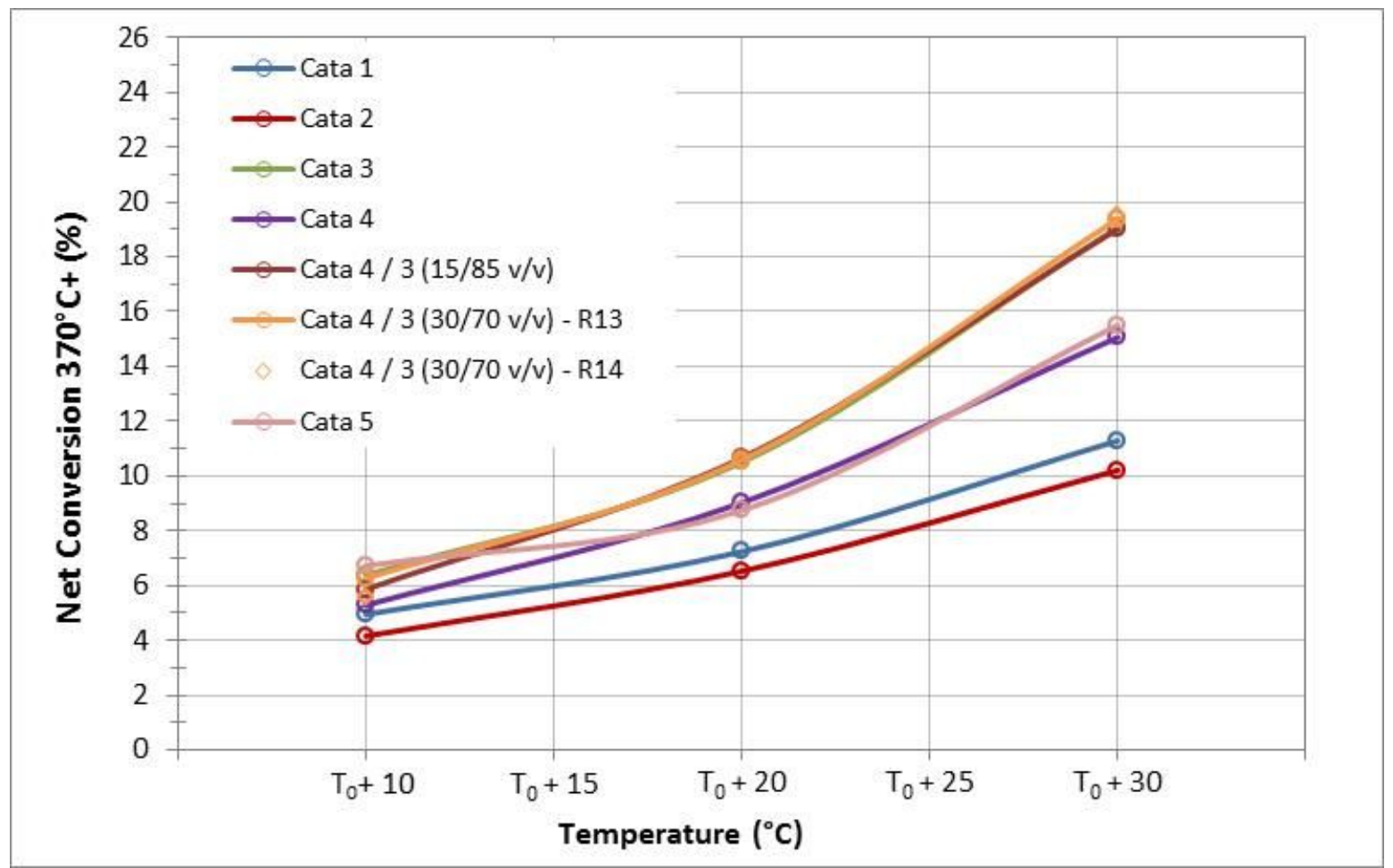

Figure S3: Sulfur content in liquid products (Feed A, LHSV=4h-1)

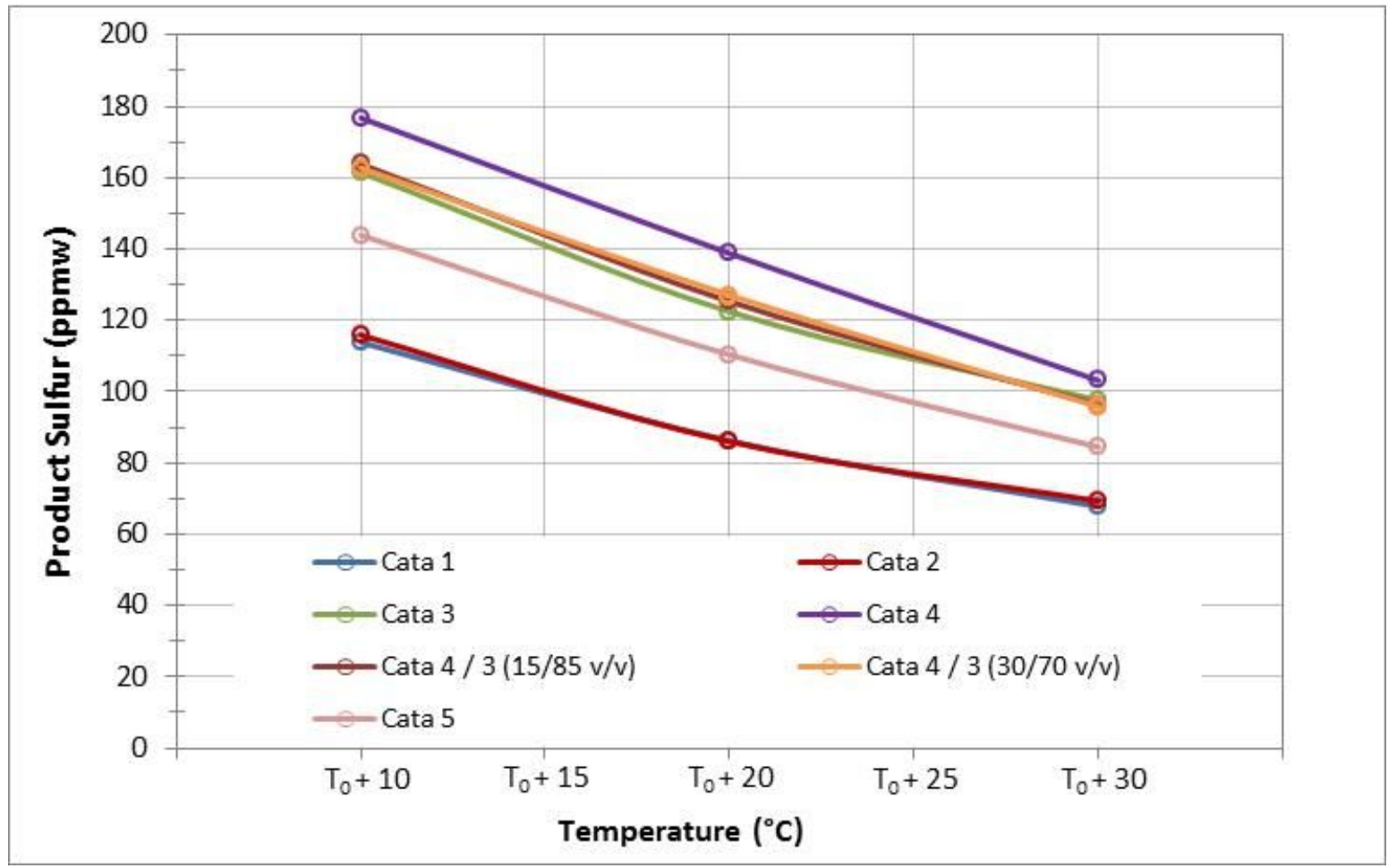

Figure S4: Nitrogen content in liquid products (Feed A, LHSV=4h-1) 


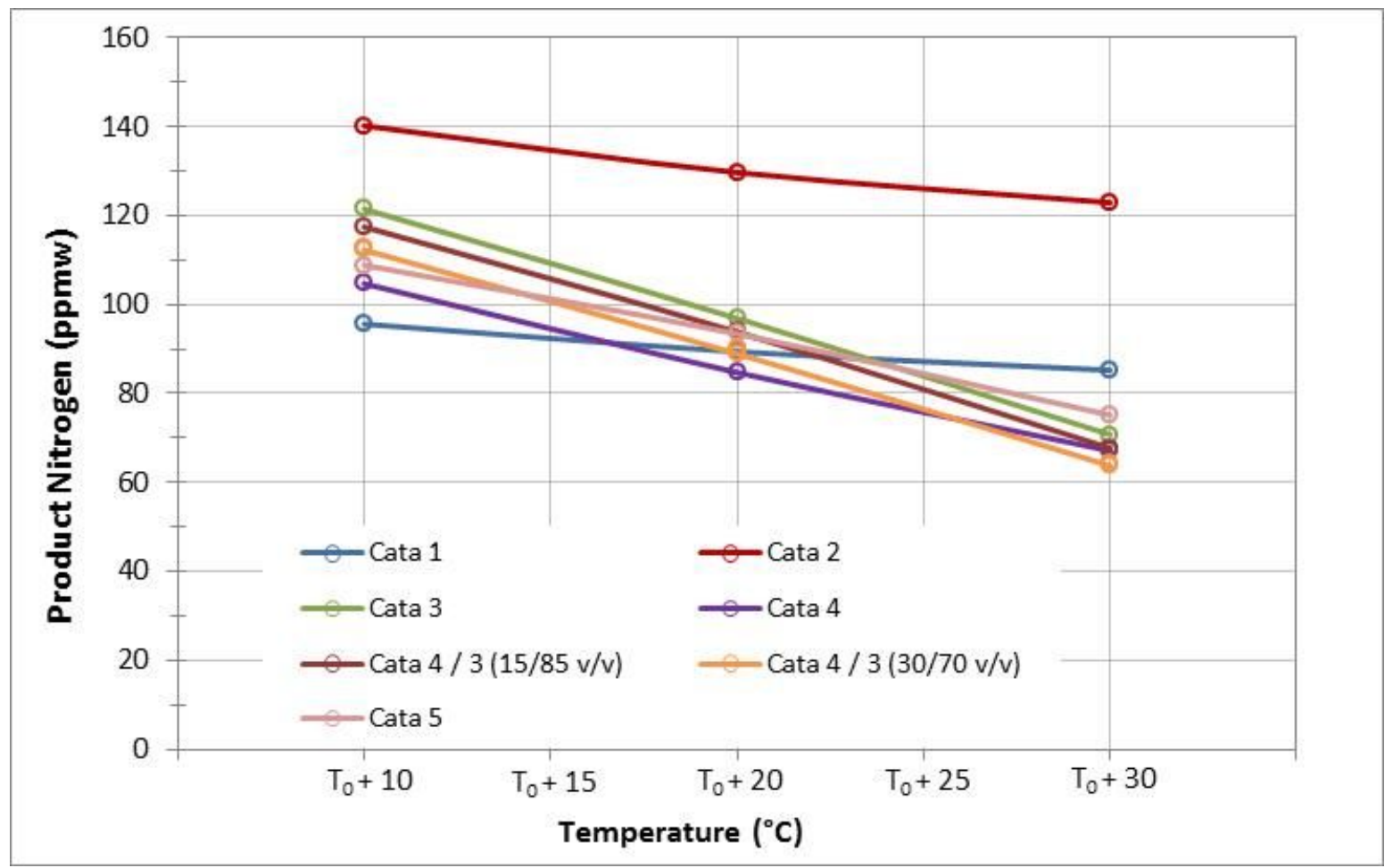

Figure S5: Net Conversion $370^{\circ} \mathrm{C}+$ with Temperature $\left(\right.$ Feed B, LHSV $=2 \mathrm{~h}^{-1}$ )

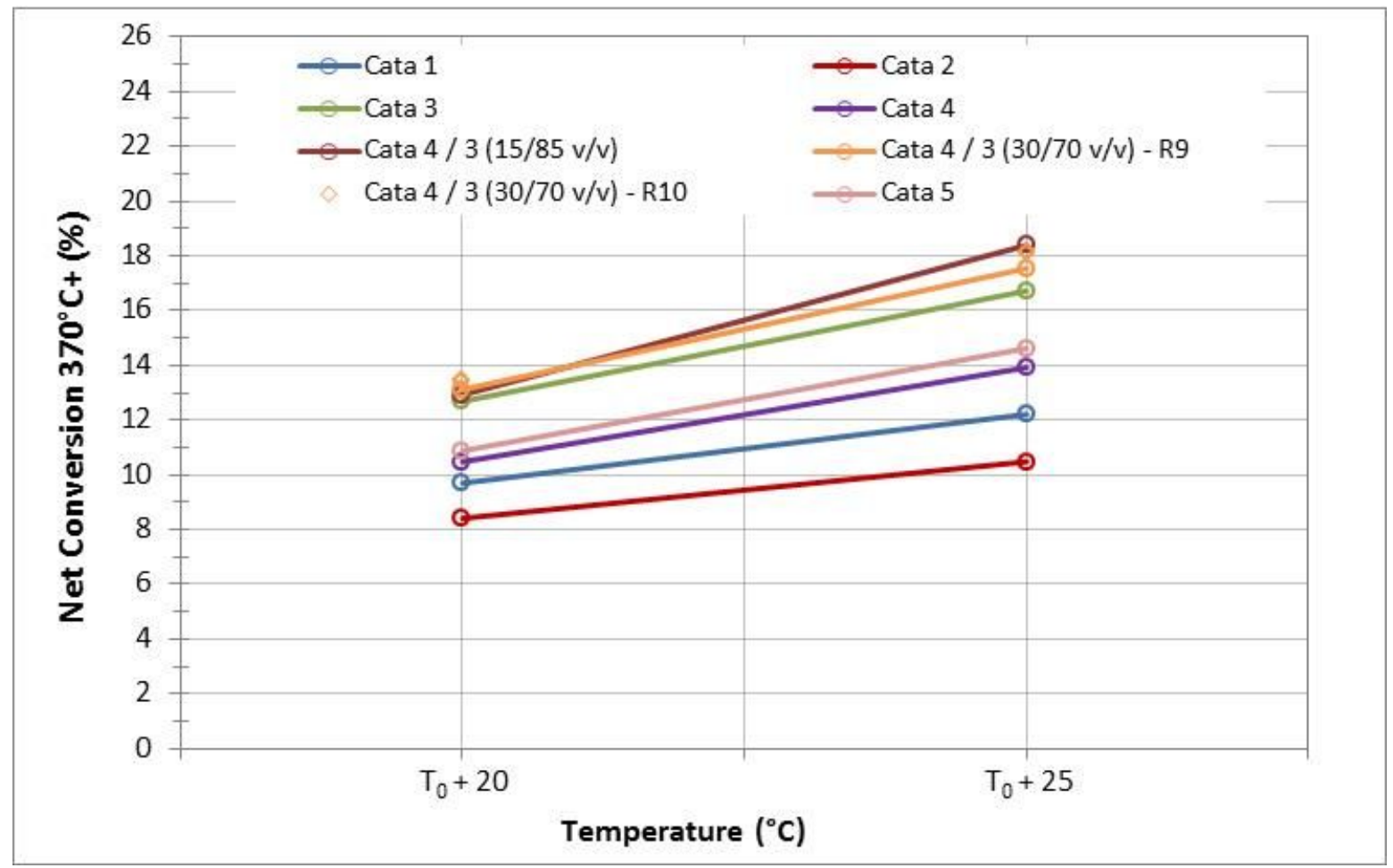


Figure S6: Net Conversion $370^{\circ} \mathrm{C}+$ with Temperature (Feed B, LHSV $\left.=4 h-1\right)$

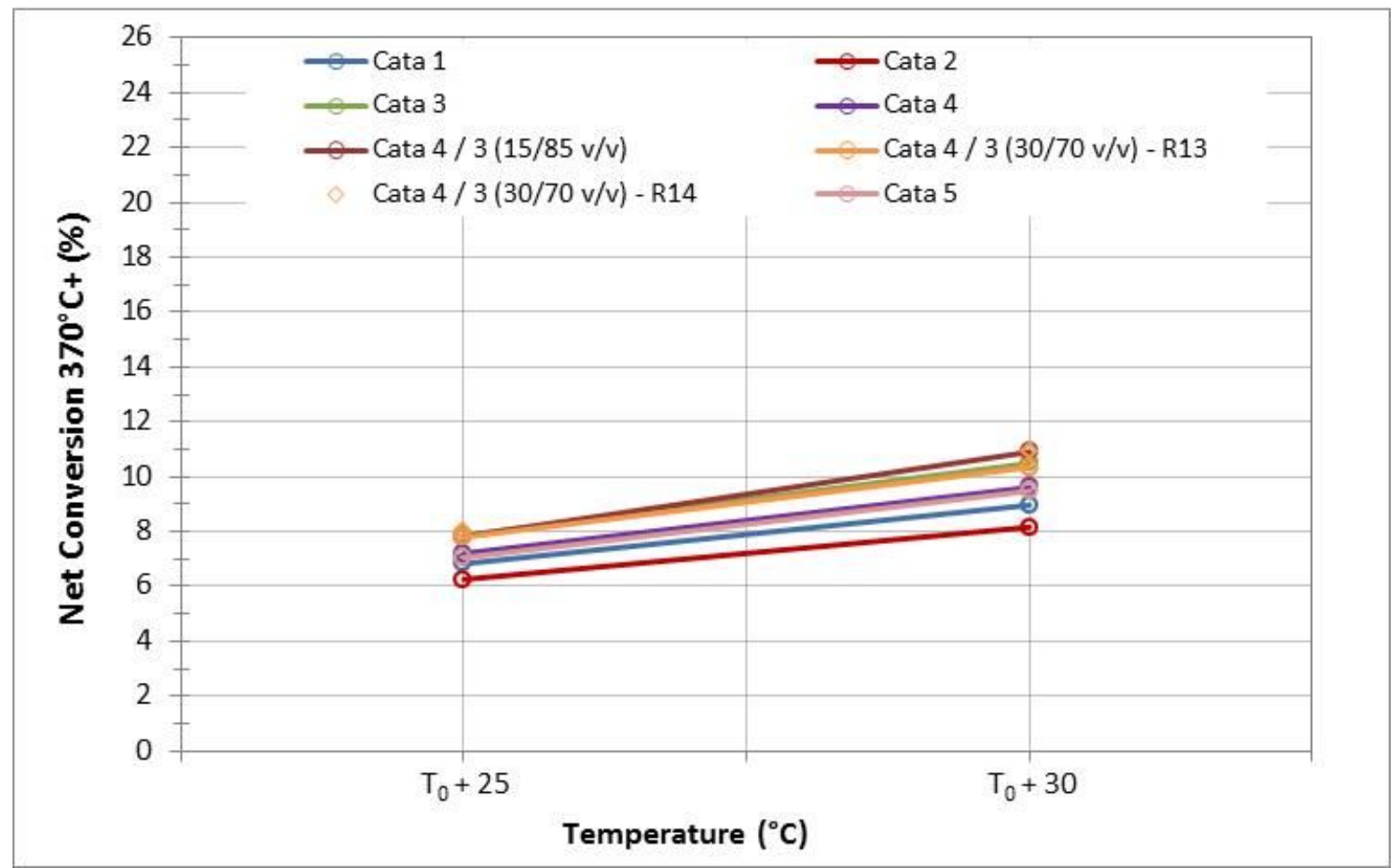

Figure S7: Sulfur content in liquid products (Feed B) 


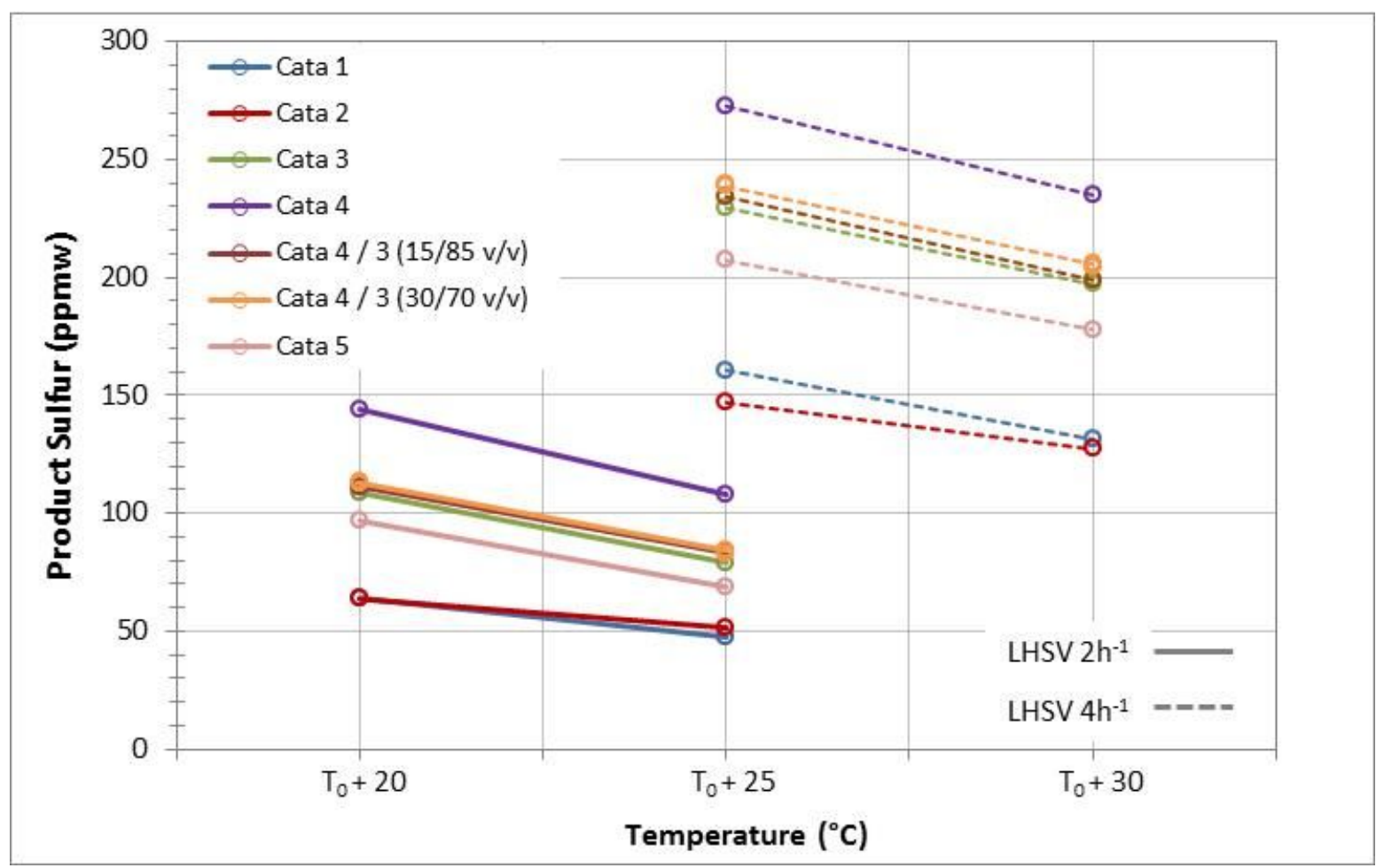

Figure S8: Nitrogen content in liquid products (Feed B)

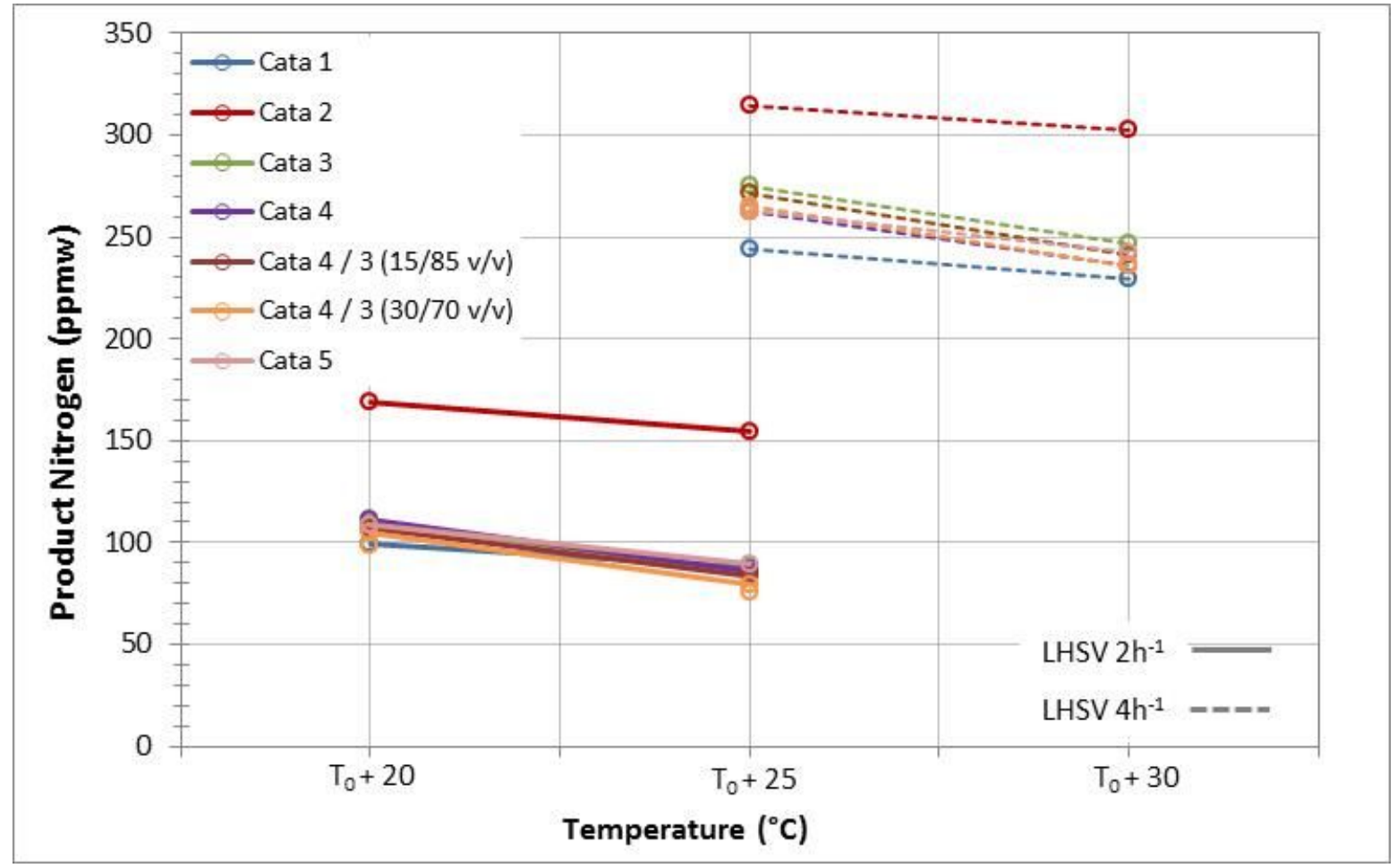

